indicative of exposure to gaseous components (e.g., aldehydes, $\left.\mathrm{NO}_{\mathrm{x}}, \mathrm{SO}_{\mathrm{x}}, \mathrm{CO}\right)$ of diesel exhaust.

Conclusion This study highlights both the historical context and the current status of exposure sampling for diesel exhaust in the occupational setting. Development of exposure sampling plans in the workplace should take into account both the timeframe of exposure (e.g., acute or chronic) and the toxicological endpoints of concern (e.g., acute irritation or chronic ailment). Furthermore, the individual assessing exposure should be aware of, and account for the differences between traditional diesel engine exhaust (TDE) and new technology diesel engine exhaust (NTDE).

\section{$1712 \mathrm{~b}$ OVERVIEW OF DIESEL ENGINE EXHAUST ISSUES}

William B Bunn. Medical University of South Carolina

\subsection{6/oemed-2018-ICOHabstracts.1152}

The mutagenicity of organic solvent extracts of diesel exhaust extracts was first noted over 60 years ago. Epidemiology and toxicology studies have resulted in classification of diesel exhaust by the International Agency for Research on Cancer (IARC) as a known carcinogen and by United States Environmental Protection Agency (USEPA) as likely to cause cancer; however, there is continued debate and quantitative risk has not been established by USEPA or environmental regulatory bodies in other countries. The major changes in diesel exhaust emissions make New Technology Diesel Exhaust (NTDE) distinct from the historic epidemiologic studies and recent animal bioassays question the relevance of studies of traditional diesel exhaust for risk assessment of NTDE.

\section{$1712 \mathrm{C}$ OCCUPATIONAL DIESEL EXHAUST EXPOSURE IN RELATION TO LUNG CANCER AND ISCHAEMIC HEART DISEASE MORTALITY}

Andreas M Neophytou, Sadie Costello, Ellen A Eisen. Environmental Health Sciences, School of Public Health, University of California, Berkeley, Berkeley, California, USA

\subsection{6/oemed-2018-ICOHabstracts. 1153}

Introduction General population studies of air pollution suggest that particles from diesel exhaust emissions are a potential risk factor for cardiovascular disease, while diesel exhaust is also classified as a known human carcinogen. We used data from the Diesel Exhaust in Miners Study to assess excess risk of lung cancer and ischaemic heart disease mortality associated with occupational diesel exhaust exposure.

Methods Analyses were performed in a cohort of non-metal miners in the US $(n=12,315)$, who were exposed to diesel exhaust. We applied the parametric g-formula to assess how hypothetical interventions setting respirable elemental carbon (surrogate for diesel) exposure limits would have impacted lifetime risk of lung cancer, and ischaemic heart disease mortality, while adjusting for time-varying employment status.

Results Lung cancer and ischaemic heart disease mortality risk decreased in association with interventions on respirable elemental carbon, with risk ratios of 0.73 (95\% confidence interval CI: 0.44 to 1.07$)$ and 0.86 (95\% CI: 0.66 to 1.12$)$ respectively, when comparing an intervention setting respirable elemental carbon exposure to zero to the observed natural course.
Conclusion Our findings suggest excess risk of lung cancer and ischaemic heart disease mortality associated with diesel exhaust exposure in this occupational setting and that interventions on exposure would have resulted in reduced risk for both outcomes.

\section{HIGH TEMPERATURE INSULATION WOOLS: STUDY OF CYTOTOXIC, GENOTOXIC/OXIDATIVE AND INFLAMMATORY EFFECTS OF POLYCRYSTALLINE WOOLS COMPARED WITH REFRACTORY CERAMIC FIBRES}

D Cavallo*, CL Ursini, A Campopiano, AM Fresegna, A Ciervo, R Maiello, A Cannizzaro, F Angelosanto, S lavicoli. Department of Occupational and Environmental Medicine, Epidemiology and Hygiene, INAIL - Italian Workers' Compensation Authority, Rome, Italy

\subsection{6/oemed-2018-ICOHabstracts.1154}

Introduction Refractory ceramic fibres (RCF) and polycrystalline wools (PCW) constitute a family of fibres known as High Temperature Insulation Wools used in industrial applications above $800^{\circ} \mathrm{C}$. Current European Classification, Labelling and Packaging of substances and mixtures classifies RCF as Category $1 \mathrm{~B}$ ('Substances presumed to have carcinogenic potential for humans'). Regarding PCW toxicity, no studies are available. We aimed to evaluate and compare cytotoxic, genotoxicoxidative and inflammatory effects of alumina-silicate RCF and PCW on human alveolar (A549) cells.

Methods SEM analysis was performed to characterise fibre dimensions. We exposed for 24 hour the cells to five different concentrations $(2-100 \mu \mathrm{g} / \mathrm{ml})$ of tested fibres to evaluate viability reduction by MTT and Trypan blue assays, membrane damage by LDH release, direct/oxidative DNA damage by Fpg comet assay and IL-6, IL-8 and TNF $\alpha$ cytokine release by ELISA.

Results SEM analysis found a length-weighted geometric mean fibre diameter $\left(\mathrm{D}^{\mathrm{LG}}\right)$ of $2.1 \mu \mathrm{m}$ with $68 \%$ of respirable fibres for RCF and a $\mathrm{D}^{\mathrm{LG}}$ of $4.2 \mu \mathrm{m}$ and $20 \%$ of respirable fibres for PCW. Moreover the content of fibres with $\mathrm{d}<3 \mu \mathrm{m}$ and $1>20 \mu \mathrm{m}$ was $44 \%$ in RCF and $11 \%$ in PCW. We found lack of viability reduction for both fibres and membrane damage induction only for RCF at $100 \mu \mathrm{g} / \mathrm{ml}$. Both the fibres induced dose-dependent DNA damage that, however, was higher for RCF reaching 5.7 fold of control vs 3.8 of PCW. Oxidative effects were induced only by RCF at the lowest concentrations. Regarding inflammatory effects, both the fibres induced only slight increase of IL-6 release at $100 \mu \mathrm{g} / \mathrm{ml}$.

Conclusion The study confirms the genotoxic/oxidative potential of RCF with thinner $\mathrm{D}^{\mathrm{LG}}$, higher percentage of respirable and longer fibres than PCW and shows genotoxicity also for PCW, suggesting also for this fibre with similar chemical composition and low biosolubility, the need of further studies to confirm such results also on other cells.

\section{SPECIFIC BIOMARKERS FOR THE EXPOSURE TO ORGANOPHOSPHATE AND CARBAMATE PESTICIDES}

Thomas Göen*, Heike Denghel, Hans Drexler. Inst. of Occupational, Social and Environmental Medicine, University of Erlangen-Nuremberg, Erlangen, Germany

\subsection{6/oemed-2018-ICOHabstracts.1155}

Introduction Organophosphate pesticides (OPP) and carbamates are still counted among the most prominent agents used for crops protection. Up to date the determination of dialkyl 
phosphates and their thio derivatives in urine is established for the OPP biomonitoring. However, this approach does not provide information on the exposure to specific OPP agents. A lot of OPP as well as some carbamates also provide specific urinary biomarkers indeed. For a specific biomonitoring approach we developed an analytical procedure, which enables the assessment of a wide spectrum of phenolic metabolites of OPP and carbamates in human urine.

Methods After enzymatic cleavage of possible glucuronide and sulfate conjugates, the analytes were extracted by solid phase cartridges and derivatized with $\mathrm{N}$-methyl-N-(trimethylsilyl)-trifluoroacetamide. The prepared samples were determined by GC-MS/MS using electron impact ionisation and multiple reaction monitoring mode. The validated method was applied to samples derived from occupational and environmental exposure.

Results The procedure enables the simultaneous quantification of 9 biomarkers for OPP exposure (4-tert-butyl-2-chlorophenol, 3-chloro-7-hydroxy-4-methylcoumarin, 2-(diethylamino)6-methylpyrimidin-4-ol, 2-isopropoxy-6-methylpyrimidin-4-ol, 3-methyl-4-(methylthio)phenol, 3-methyl-4-nitrophenol, 4(methylthio)phenol, 4-nitrophenol, 3,5,6-trichloro-2-pyridinol) and 7 biomarkers for carbamate exposure (2-amino-5,6-dimethylpyrimidin-4-ol, 2-(dimethylamino)-5,6-dimethyl-pyrimidin4-ol, 2,2-dimethylbenzo[1,3]dioxol-4-ol, 2,2-dimethyl-2,3-dihydrobenzofuran-7-ol, 3,5-dimethyl-4-(methylthio)phenol, 2-isopropoxyphenol, 1-naphthol).The method showed detection limits between 0.1 and $0.3 \mu \mathrm{g} / \mathrm{L}$. Variation coefficients ranged from $2 \%$ to $10 \%$ for precision in series and $2 \%$ to $14 \%$ for inter-day precision. Furthermore, recovery rates between $87 \%$ and $120 \%$ were determined.

Discussion The method showed high reliability and robustness. It enables the simultaneous and specific monitoring of a wide spectrum of pesticides and biocides whose structures contain aryl moieties. The multicomponent procedure can be used for biomonitoring of agriculture workers, bystanders and general populations.

\section{URINARY TRIMETHYLTIN REFLECTS BLOOD TRIMETHYLTIN IN SCRAP RECYCLING WORKERS}

${ }^{1} \mathrm{G}$ Ichihara*, M lida, T Fujie, T Kaji, ${ }^{2} Y$ Kim. ${ }^{1}$ Tokyo University of Science, Noda, Japan; ${ }^{2}$ University of Ulsan College of Medicine, Ulsan, Korea

\subsection{6/oemed-2018-ICOHabstracts. 1156}

Introduction We recently reported cases of scrap recycling workers intoxicated with organotin, who showed severe encephalopathy with symptoms of memory disturbance. The study showed higher ratio of urinary trimethyltin to urinary dimethyltin in the workers than that in the previous cases exposed to only dimethyltin, suggesting co-exposure to dimethyltin and trimethyltin in the present cases. The present study subsequently investigated blood dimethyltin and trimethyltin to understand the relationship of urinary and blood dimethlytin/ trimethyltin for evaluation of validity of them as exposure markers for organotin.

Methods Urinary and blood dimethyltin and trimethyltin at different time points in three workers were measured with HPLC-ICP/MS. Regression analyses were conducted with independent values of blood dimethyltin and trimethyltin and dependent values of urinary dimethyltin and trimethyltin respectively. Multiple regression analysis with dummy variable of individual was also conducted for adjustment of individual factors.

Result Regression analysis showed significantly positive relation of urinary trimethyltin to blood trimethyltin, but did not show significant relation of urinary dimethyltin to blood dimethyltin. Multiple regression analysis with individual factor also showed significantly positive relation of urinary trimethyltin to blood dimethyltin.

Discussion The study shows that urinary trimethyltin reflects blood trimethyltin. In co-exposure to trimethytin and dimethyltin, urinary trimethyltin can be an internal exposure marker of trimethyltin, which is considered to be not only derived from external exposure to trimethyltin but also the trimethyl tin converted from dimethyltin, in human body.

\section{HUMAN BIOMONITORING FOR EXPOSURE ASSESSMENT OF BENZENE DURING SHORT-TERM MAINTENANCE WORK}

T Jäger*, S Bäcker, C Oberlinner, M Bader. BASF SE, Corporate Health Management, Ludwigshafen, Germany

\subsection{6/oemed-2018-ICOHabstracts. 1157}

Introduction Human biomonitoring (HBM) is frequently used for exposure analysis and assessment of maintenance workers potentially exposed to benzene during turnaround works. In Germany, the Technical Rule for Hazardous Substances (TRGS) 910 provides three biomarkers for benzene: S-phenylmercapturic acid (SPMA), trans, trans-muconic acid (ttMA) and unmetabolized benzene in urine. The aim of the present HBM study was to compare the validity and applicability of the different biomarkers for exposure assessment during a turnaround.

Methods In 2016, 143 post-shift urine samples of 119 maintenance workers with potential exposure to benzene were analysed. In each sample urinary benzene, SPMA and ttMA were measured according to procedures recommended by the German Research Foundation (DFG). The biomonitoring equivalents of the tolerance concentration according to the TRGS 910 were used as internal action values: $0.5 \mathrm{mg}$ ttMA/g creatinine, $25 \mu \mathrm{g} \mathrm{SPMA} / \mathrm{g}$ creatinine, $5 \mu \mathrm{g}$ benzene/L urine.

Results The median values were $0.09 \mathrm{mg} / \mathrm{g}$ creatinine (range: $<$ LOQ - $1.76 \mathrm{mg} / \mathrm{g}$ creatinine) for ttMA, <LOQ (range: $<\mathrm{LOQ}-73.5 \mu \mathrm{g} / \mathrm{g}$ creatinine) for SPMA and $0.5 \mu \mathrm{g} / \mathrm{L}$ (range: $0.1-9.9 \mu \mathrm{g} / \mathrm{L}$ ) for urinary benzene. Action value excursions were observed in less than $2 \%$ of the post-shift samples for SPMA, 4\% for ttMA and 7\% for urinary benzene, respectively. However, the results showed that the action value excursions were not necessarily observed in the same samples, probably resulting from, e.g., peak exposures and different elimination half-lives.

Conclusion The HBM program has shown a low overall occupational exposure to benzene during turnaround works. With respect to applicability and validity, urinary SPMA is the biomarker of choice for the reliable HBM of benzene exposures. ttMA has a critically low diagnostic sensitivity, while unmetabolized urinary benzene demands special attention to avoid external contamination. Nevertheless, urinary benzene allows for a rapid and relatively cost-efficient analysis and it is well suitable for screening purposes. 